\title{
Outcome of Type 1 tympanoplasty: An experience at Biratnagar eye hospital in Eastern Nepal
}

\author{
Sanjeev Kumar Thakur', Sanjay Kumar Singh², Anwar Afaque ${ }^{3}$, Nisha Ghimire ${ }^{4}$ \\ ${ }^{1}$ ENT Consultant, Ear Department, Biratnagar Eye Hospital \& Lecturer, Nobel Medical College, Biratnagar, Nepal, ${ }^{2}$ Consultant Ophthalmologist \\ and Programme Director, Biratnagar Eye Hospital, Biratnagar, Nepal, ${ }^{3}$ Health Educator, Biratnagar Eye Hospital, Biratnagar, Nepal, ${ }^{4}$ Assistant \\ Professor, Department of Physiology, Nobel Medical College, Biratnagar, Nepal
}

Background: The history of tympanoplasty is well over a century. Type 1 tympanoplasty is an established procedure worldwide with a variation in the outcome. Aims and Objectives: To analyze the outcome of Type 1 tympanoplasty surgeries in terms of graft success and hearing improvement done at the Ear Department of Biratnagar eye hospital in eastern Nepal and discuss the various factors that might have influenced it. Materials and Methods: Retrospective analysis of records of the cases that underwent Type 1 tympanoplasty from August 2013 to January 2015 was done. The factors analysed were age, gender, the side of the affected ear and the perforation size. Appropriate Statistical test was applied and the results were discussed. Results: A total of 151 cases of type 1 Tympanoplasty were analysed were females had higher frequency than males, with higher incidence at younger age. The mean age of successful cases was 28.53. Females had a better success rate in terms of graft success compared to males. Moderate size perforations had the best outcome of graft success and least were of small size perforations. Of all cases analyzed, hearing improvement was observed in maximum cases. Conclusion: There was no significant influence of age or gender on the hearing outcome. The difference of hearing improvement according to size of perforation was also not significant.

Key words: Tympanoplasty, otitis media, hearing loss.

\section{INTRODUCTION}

Despite of all the scientific developments (antibiotics, technology and knowledge), the Otitis media is still considered an important public health problem worldwide. It is also quite common in eastern Nepal. ${ }^{1}$ Long standing perforation leads to recurrent ear discharge that needs surgical corrections like tympanoplasty. Type 1 Tympanoplasty, as classified by Wullstein in 1956, aims to reconstruct the tympanic membrane and restore the sound hearing mechanism over the intact and mobile ossicles through exploratory tympanotomy with cessation of otorrhea. ${ }^{2}$ The history of tympanoplasty is well over a century, but there were lots of complications in early days. The real advance was made in the early 1950's and 1960's with the advent of antibiotics, operating microscopes, temporalis fasciae and other materials. ${ }^{3}$ Nowadays, it is one of the popular operations in the ear, nose and throat (ENT) units all over the world with underlay technique and temporalis fascia. ${ }^{4}$

Though very common and established procedure and despite several known prognostic factors that may affect the surgical outcome, failures have been reported in the literature. The success rate in the literature shows a wide variation. $^{5}$

The quest is to improve the results further by studying the different factors that could possibly affect the outcome. Different authors have described different factors and technical elements to modify the outcome of tympanoplasty. It is important to set up prerequisites for selecting the patients for surgery in order to optimize the result. ${ }^{6}$ 
Therefore, in our efforts to achieve better results, in terms of graft success and better hearing, this retrospective study aims to analyze the outcome of Type 1 tympanoplasty surgeries done at the newly established Ear Department of Biratnagar eye hospital, Biratnagar in eastern Nepal and discuss the various factors that might have influenced it. Relevant literature and various methodologies were also reviewed. ${ }^{7,8}$

\section{AIMS AND OBJECTIVES}

To analyze the outcome of Type 1 tympanoplasty surgeries in terms of graft success and hearing improvement done at the Ear Department of Biratnagar eye hospital in eastern Nepal and discuss the various factors that might have influenced it.

\section{MATERIALS AND METHODS}

A retrospective study was carried out of the operation records of tympanoplasty type- 1 during the years August 2013 through to January 2015, at Biratnagar Eye Hospital in Eastern Nepal.

All these patients had this surgery under local anesthesia, through postaural approach by the same ENT surgeon using temporalis fascia as the only grafting material. The patients with incomplete and missing files and the ears with other types of tympanoplasty or cholesteatoma were excluded. The ears with mixed or sensorineural hearing loss were also excluded. All the patients followed up postoperatively for more than 2 months were included. The ears selected were dry for at least one month prior to surgery and they all had preoperative and postoperative pure tone audiograms, with appropriate masking as required, according to World Health Organisation (WHO) guidelines. ${ }^{9}$ The hearing threshold level, using audiometry, was taken as the average for four frequencies $0.5,1,2$, and $4 \mathrm{kHz}$ for Air-conduction. Hearing improvement was assessed by closure of the air bone gap.

Thus, 151 ears were selected in this study, which fulfilled all the above mentioned criterias. Those ears with intact tympanic membrane and clinical improvement of hearing were considered successful while the others with residual defects, infections or any other complication at the end of 2 months and more follow-up were categorized as failure. All these data and the factors presumed to influence results were detailed in a setup proforma and tables, and the results were analyzed using statistical package for social sciences (version 10.0.1 for Windows). Appropriate statistical tests were used to calculate the graft success rates and hearing improvement. The results were considered statistically significant when $\mathrm{p}$ value $<0.05$.

\section{RESULTS}

A total of 151 cases of type 1 Tympanoplasty were analysed. The age range was 13-50 years, with a mean of 28.23 and standard deviation 9.7. Overall, 58 male and 93 female underwent Type 1 tympanoplasty, with a sex ratio of Female: Male being 1.6:1. The Table 1 illustrates the range and frequency of the study population, highest frequency being of the age group 21-30 years, followed by those of 13-20 years. Table 2 shows the analysis of parameters of age on success of type 1 tympanoplasty of the study group. The mean age of successful group was 28.53 and standard deviation 9.82 .

One-hundred thirty nine out of 151 operated upon had graft success, amounting to $92.05 \%$ as shown in Table 3. Female: male ratio was 1.73:1 in the successful group. Females $(63.3 \%)$ had a better success rate in terms of graft success than males $(36.7 \%)$, with a p-value of 0.146 . $65(43 \%)$ right ears and $86(57 \%)$ left ears were operated upon, and right ears had a better graft success (95.4\%), compared to those of left ears $(89.6 \%)$, with a $\mathrm{p}$-value of 0.176 . The perforation size was classified in to small, moderate and subtotal size perforation. ${ }^{8} 10$ According to perforation size, moderate size perforations had the best outcome (94.3\%) in terms of graft success, followed by subtotal size perforation $(93 \%)$ and small size perforation $(70 \%)$ with a p-value of 0.093 . None of the factors analysed above had any statistical significance, though. 99 (65.56\%) ears were followed up for 2 months, $44(29.14 \%)$ ears were followed for 2-12 month and only $8(5.29 \%)$ ears for more than 1 year.

Hearing improvement was seen in $125(82.8 \%)$ cases operated upon, worse in $8(5.3 \%)$ cases and no change in

\begin{tabular}{|c|c|c|c|c|}
\hline Age range & Male & Female & Total & Percentage \\
\hline $13-20$ & 25 & 17 & 42 & 27.8 \\
\hline $21-30$ & 19 & 35 & 54 & 35.8 \\
\hline $31-40$ & 10 & 28 & 38 & 25.2 \\
\hline $41-50$ & 4 & 13 & 17 & 11.3 \\
\hline Total & 58 & 93 & 151 & 100 \\
\hline Percentage & 38.4 & 61.6 & 100 & \\
\hline
\end{tabular}

\begin{tabular}{lcc}
$\begin{array}{l}\text { Table 2: The mean age and range in Type } 1 \\
\text { tympanoplasty }\end{array}$ & Age-operated \\
group (N=151) & $\begin{array}{c}\text { Age-successful } \\
\text { group (N=139) }\end{array}$ \\
\hline Parameter & 28.23 & 28.53 \\
\hline Mean & 9.7 & 9.82 \\
Std deviation & 13 & 13 \\
Minimum & 50 & 50 \\
Maximum & & \\
\hline
\end{tabular}




\begin{tabular}{|c|c|c|c|c|}
\hline Factors & $\begin{array}{l}\text { Overall number } \\
\text { of cases } N=151\end{array}$ & $\begin{array}{c}\text { Graft success } \\
n=139\end{array}$ & $\begin{array}{l}\text { Graft success } \\
\text { rate in percentage }\end{array}$ & P-value \\
\hline $\operatorname{Sex}(\%)$ & & & & 0.146 \\
\hline Female & $93(61.6)$ & $88(63.3)$ & 94.6 & \\
\hline Male & $58(38.4)$ & $51(36.7)$ & 88 & \\
\hline Male:Female & 1:1.6 & $1: 1.73$ & & \\
\hline Affected ear (\%) & & & & 0.176 \\
\hline Right & $65(43)$ & $62(44.6)$ & 95.4 & \\
\hline Left & $86(57)$ & $77(55.4)$ & 89.6 & \\
\hline Middle ear status at surgery & All dry & & & \\
\hline Perforation size $(\%)$ & & & & 0.093 \\
\hline Subtotal & $71(47)$ & $66(47.5)$ & 93 & \\
\hline Moderate & $70(46.4)$ & $66(47.5)$ & 94.3 & \\
\hline Small & $10(6.6)$ & $7(5)$ & 70 & \\
\hline
\end{tabular}

status of hearing in $18(11.9 \%)$ cases as shown in Table 4 . All the 10 cases with small perforation had hearing improved.

The Preoperative hearing loss had a mean of $37.3 \mathrm{~dB}$ and the postoperative hearing loss had a mean of $29.8 \mathrm{~dB}$, as shown in Table 5. The mean hearing loss improvement was $7.64 \mathrm{~dB}$. Overall, 139 (92.1\%) patients had hearing improvement by less than or equal to $15 \mathrm{~dB}$. However, $12(7.9 \%)$ patients had hearing improvement by more than $15 \mathrm{~dB}$. On, further analysis of influence of age ( $p$ value 0.54 ) and gender ( $p$ value 0.706 ) on hearing improvement, these factors were not found to be significant.

Table 6 demonstrates the hearing improvement according to size of perforation. Out of 71 subtotal perforation cases, $56(78.3 \%)$ had hearing improved, 7 (9.9\%) had worsening of hearing and $8(11.3 \%)$ had no change in hearing. Out of 70 cases with moderate perforation, 59 (84.3\%) had hearing improved, $1(1.4 \%)$ case had worsening of hearing and $10(14.3 \%)$ cases had no change in hearing. The p-value was 0.118 .

\section{DISCUSSION}

A total of 151 cases of type 1 Tympanoplasty were analysed. The age range was $13-50$ years, with a mean of 28.23. Female were more common than male, with a sex ratio of Female: Male being 1.6:1. The highest frequency was of the age group 21-30 years, followed by those of 13-20 years in our study.

In a study by Krishna and Devi in 2013, female were more common than male, similar to our study. ${ }^{7}$ Similarly, in a study by Shetty in 2012 female were more common than male, and younger age group being more common (11-30 years), with a mean age of 23.5 years. ${ }^{11}$ However, other studies had male more common than female, though younger age groups were more common in all these studies. ${ }^{12,13}$

\begin{tabular}{lcc} 
Table 4: Hearing Improvement & \\
\hline Category & Number & Percentage \\
\hline Improved & 125 & 82.8 \\
Worse & 8 & 5.3 \\
Same & 18 & 11.9 \\
Total & 151 & 100 \\
\hline
\end{tabular}

\begin{tabular}{lc} 
Table 5: Overall analysis of hearing loss \\
\hline Mean hearing loss improvement \\
Preoperative air-bone gap (mean) & $7.64 \mathrm{~dB}$ \\
Preoperative air-bone gap (median) & $37.27 \mathrm{~dB}$ \\
Postoperative air-bone gap (mean) & $36 \mathrm{~dB}$ \\
Postoperative air-bone gap (median) & $29.81 \mathrm{~dB}$ \\
Preoperative range & $29 \mathrm{~dB}$ \\
Postoperative range & $13-81 \mathrm{~dB}$ \\
\hline
\end{tabular}

Table 6: Hearing improvement according to size
of perforation (P-value=0.118)
\begin{tabular}{lcccc} 
Category & Subtotal & Moderate & Small & Total (percentage) \\
\hline Improved & $56(78.3)$ & $59(84.3)$ & $10(100)$ & $125(82.8)$ \\
Worse & $7(9.9)$ & $1(1.4)$ & 0 & $8(5.3)$ \\
Same & $8(11.3)$ & $10(14.3)$ & 0 & $18(11.9)$ \\
Total & $71(47)$ & $70(46.6)$ & $10(6.6)$ & $151(100)$ \\
(percentage) & & & & \\
\hline
\end{tabular}

The involvement of young age groups being more common indicates the fact that Chronic suppurative otitis media (CSOM) is mainly the middle ear infection which tends to occur more in early decades of life and resolves to leave permanent perforations with conductive hearing loss in many cases. ${ }^{11}$

One-hundred thirty nine out 151 operated upon had graft success, amounting to $92.05 \%$. Female: male ratio was 1.73:1 in the successful group. Females $(63.3 \%)$ had a better success rate in terms of graft success than males $(36.7 \%)$, with a p-value of 0.146 .

The success rate of tympanoplasty type-1, reported in literature considering various factors, ranged between 80 - 97\% depending on follow up period. $8,14,15$ 
Considering the factors influencing the outcome, the age factor did not influence the success rate in terms of graft success, in our study, as shown in Table 2. In their study Warren \& Benjamin found the age of patient to have no affect on success of tympanoplasty. ${ }^{16}$ Similarly, Fadl, in his study, found age factor to have no influence on graft success. $^{8}$

However, a recent study in Nepal Medical College concluded that the graft takes rate was better with the advancing ages. ${ }^{17}$

In a study conducted by N Gupta and R K Mishra in 2002, the success rate was observed to be slightly higher in 12-15 year age group (90.24\%) than in 8-11 year age group $(81.8 \%){ }^{18}$

Tympanoplasty in children was not favored in our study. Many tympanic membrane perforations heal spontaneously and generally children are more prone to recurrent upper respiratory tract infections in addition to the difficulties to waterproof the ears postoperatively. However, tympanoplasty in children has always been a controversial subject since many authors feel that many developmental processes in children constitute an unfavorable prognostic factor to success of the procedure. ${ }^{19}$

But other studies found tympanoplasty in children quite successful. ${ }^{20,21}$ In 1994 study published by Alexander Kessler and colleagues concluded that reperforation was more common in patients younger than 6 years. ${ }^{22}$

Sixty-five (43\%) right ears and $86(57 \%)$ left ears were operated upon, and right ears had a better graft success (95.4\%), compared to those of left ears $(89.6 \%)$, with a p-value of 0.176 .

In our series, the factors such as gender and the side of the affected ear (right or left), similar to another study, did not influence the overall success rates. ${ }^{8,23}$ However, Feroze, Rejee and Sajilal found better outcome in male gender. ${ }^{24}$

Comparing the graft success rates, according to perforation size, subtotal perforation $(93 \%)$, with that of moderate sized perforation (94.3\%) or small sized perforation (70\%), there was no statistical significant difference ( $\mathrm{p}$ value 0.093), similar to the study by Fadl AF. ${ }^{8}$ Similarly, Saeed and Ghamdi in their study found that the size and site of perforations had no effect on surgical success. ${ }^{12}$

Lee et al found the success rate for small perforations higher (74.1\%) compared to large perforations (56\%). ${ }^{25}$ Our study had lower success rate for small perforation compared to moderate size and subtotal perforation, however, the number of small size perforation was less, only ten cases. This study has shown better success rate in moderate size perforation compared to subtotal perforation, but Gersdorff achieved best results with subtotal perforations, and not with partial posterior perforations. ${ }^{26}$

Warren $\mathrm{Y}$ and colleagues found that the two factors which adversely influenced the success rate were the presence of a near total or total perforation and the presence of bilateral perforations. ${ }^{16}$ However, we did not assess the influence of bilateral perforation as factor.

The technique of choice in our series was the popular underlay technique with temporalis fascia as graft material. This technique is the standard practice worldwide and the results achieved were quite satisfactory. ${ }^{4,15}$ The temporalis fascia can easily be harvested through the same postaural incision. However, it was important to take up measures to prevent catarrhal infections, appropriate wound dressing, keeping the ear dry before and after surgery and antibiotics therapy. However, Fadl AF found that despite the relative small numbers, permeatal approach had statistical significant $\mathrm{p}$ value $(\mathrm{p}<0.045)$ compared to endaural approach. ${ }^{8}$ Also it had a higher success rate $(95.8 \%)$ than both endaural $(78.3 \%)$ and postaural $(92.3 \%)$ approaches. But, Saeed and Ghamdi found no influence of surgical approach on the outcome. ${ }^{12}$

Fadl found that the middle ear status at surgery whether wet $(6.2 \%)$ or dry $(93.8 \%)$ showed nearly similar results of success. (83.3\% and $84.6 \%$ respectively). ${ }^{8}$ Halik and Smyth found that the type of middle ear secretion present at surgery had no effect on the result. ${ }^{27}$ Nagle and colleagues, concluded that the presence of mucoid and scanty discharge in the ear at the time of operation did not interfere with the results of Tympanoplasty. ${ }^{28}$ However, all the ears in our study were dry.

Vijayendra $\mathrm{H}$ et al found that the failure rate in totally dry ear Tympanoplasty was more as compared to wet Tympanoplasty mainly because of the avascularity of remnant tympanic membrane in totally dry central perforation. ${ }^{29}$ Saeed and Ghamdi found no patient with a discharging ear had a successful surgery. ${ }^{12}$

Zakaria and colleagues in their results showed that the condition of middle ear at the time of operation affects the surgical outcome. Graft take rate was greater in dry perforation. Hearing improvement was greater in dry perforation. ${ }^{30}$

Hearing results are determined by the extent of initial damage to the tympanic membrane \& ossicles and whether or not the tympanic cavity becomes properly aerated 
after tympanoplasty. ${ }^{31}$ Hearing improvement was seen in $125(82.8 \%)$ cases operated upon, worse in $8(5.3 \%)$ cases and no change in status of hearing in $18(11.9 \%)$ cases, in our study.

In a recent study done in 2015, amongst the patients who underwent Type I tympanoplasty, 66.6\% showed hearing improvement and $33.3 \%$ remained the same and none worsened. ${ }^{32}$

According to Feroz and colleagues, the degree of hearing loss did not affect the success rate. ${ }^{24}$

All the 10 cases with small perforation had hearing improved. Although the hearing improvement was better in moderate size perforation $(84.3 \%)$ than in subtotal perforation $(78.3 \%)$, the difference was not statistically significant(p-value 0.118) similar to the study by Fadl. ${ }^{8}$

In our study, the preoperative hearing loss had a mean of $37.3 \mathrm{~dB}$ and the postoperative hearing loss had a mean of $29.8 \mathrm{~dB}$. The mean hearing loss improvement was $7.64 \mathrm{~dB}$. On, further analysis of influence of age ( $p$ value 0.54$)$ and gender ( $p$ value 0.706 ) on hearing improvement, these factors were not found to be significant.

In a recent study done, the average hearing gain in $\mathrm{db}$ observed in the study population was $7.7 \mathrm{~dB}$. ${ }^{7}$ Palva \& Ramsay in a study done in 1995 reported a mean hearing improvement of $8.0 \mathrm{~dB}$ in their studies. ${ }^{33}$

In a study by Sirena $\mathrm{E}$ and colleagues, they observed an average improvement of $12.3 \mathrm{~dB} .{ }^{34}$

$99(65.56 \%)$ ears were followed up for 2 months, $44(29.14 \%)$ ears were followed for 2-12 month and only $8(5.29 \%)$ ears for more than one year. Postoperative follow up of at least 1 year was done by Feroz and colleagues. ${ }^{24}$ However, long term follow-up for more than 2 years is prescribed to declare the successful tympanoplasty and serviceable hearing. ${ }^{7}$ Doyle and colleagues, reported a recurrence of perforation in $17 \%$ of patients at one year and $12 \%$ after 3 years in 79 ears which had been operated on by underlay technique. ${ }^{35}$

However, as the compliance of patients for follow-up fell after 2 months, it was difficult to evaluate the long term results.

The study has made an attempt to analyse the outcome and affecting factors, in terms of graft uptake and also interpreting hearing gain after Type 1 Tympanoplasty. However, uniform data may not be obtained in all of the variables studied because of observer variation in various studies. The variables are analyzed separately by various authors, but in clinical practice all these factors are interconnected and act concomitantly in disease morbidity. ${ }^{7}$

\section{Limitations of the study}

There were less number of pediatric cases in our study, though authors differ on the results of outcome of Type 1 tympanoplasty as discussed above. The status of contralateral ear was not analysed in this study, which might have influenced the outcome of surgery. Several authors have reported a better outcome in unilateral perforations than in the bilateral disease. ${ }^{16,24}$ Smoking status was not analysed, though several authors have found it as a significant prognostic factor influencing the success rate of tympanoplasty negatively. ${ }^{36}$

Similarly, Eustachian tube dysfunction was not analysed separately, but many authors agree that preoperative abnormalities indicative of severity of underlying Eustachian tube dysfunction and infection have a significant influence on prognosis.

There were no cases of wet ear in our study, though several authors have found no influence of status of wet and dry ear on the the outcome. ${ }^{12,30}$ The site of perforation was not analysed separately but it influences the outcome as shown by Zakaria and colleagues. ${ }^{30}$

All the cases had same approach (postaural), though Fadl found influence of permeatal approach to be better than postaural approach. ${ }^{8}$ Although, the follow up time was ranging from 2 months to 1 year, long term follow up might find more true picture of outcome as found by several authors and discussed above.

Hence, a long term follow up study, that would also address the above mentioned limitations should be done to achieve a better insight pertaining as to the outcome of Type 1 tympanoplasty.

\section{CONCLUSION}

In spite of several limitations to this study, surgical and audiometric outcome obtained might be accepted as satisfactory and as expected by the results of published literature from elsewhere. The factors (gender, age, side of ear operated and size of perforation) presumed to influence the graft success in Type 1 tympanoplasty was statistically not significant. There was no significant influence of age or gender on the hearing outcome. The difference of hearing improvement according to size of perforation was also not significant. A long term follow up study with inclusion of unaddressed factors should be done. 


\section{REFERENCES}

1. Upadhyay MP. Sunsari health examination survey, BPKIHS, 1996.

2. Hirsch BE. Myringoplasty and Tympanoplasty. In: Eugene N Myers, editor. Operative Otolaryngology/Head \& Neck Surgery. 2nd edn. Saunders; 2008; 1246 - 1261.

3. Wullstien $\mathrm{H}$. In retrospect of a surgeon. In: Lang WH, Muchel F, editors. Zeiss Microscope for Microsurgery. Berlin (DE): Springer-Verlag; 1981.

4. Frootko NJ. Reconstruction of the middle ear. In: Booth JB, editors. Scott-Brown's Otolaryngology. Vol. 3. Oxford (UK): Butterworth-Heinemann; 1997. p. 3/11/1-3/11/30.

5. Ravishankar C, Dhanapala N and Rajput R. A Review of Results of Type I Tympanoplasty in Active and Inactive Tubotympanic Chronic Suppurative Otitis Media. Research in Otolaryngology 2014; 3(5): 77-80

6. Onal K, Uguz MZ, Kazikdas KC, Gursoy ST and Gokce H. A multivariate analysis of otological, surgical and patient-related factors in determining success in myringoplasty. Clin Otolaryngol 2005; 30:115-120.

7. Krishna PH and Devi TS. Clinical Study of Influence of Prognostic Factors on the Outcome of Tympanoplasty Surgery. IOSR Journal of Dental and Medical Sciences 2013; 5(6): 41-45.

8. Fadl AF. Outcome of type-1 tympanoplasty. Saudi Med J 2003; 24 (1): 58-61.

9. WHO Report of the Informal Working Group On Prevention Of Deafness And Hearing Impairment Programme Planning. Geneva, 1991

10. METEOR, Metadata online registry, Australian institute of Health and Welfare. Patient- Tympanic Membrane Perforation size, code-N. http://meteor.aihw.gov.au/content/index.phtml/ itemld/498159 [Accessed on 9 july 2015]

11. Shetty S. Pre-Operative and Post-Operative Assessment of Hearing following Tympanoplasty. Indian J Otolaryngol Head Neck Surg 2012; 64(4): 377-381.

12. Saeed A and Ghamdi Al. Tympanoplasty: factors influencing surgical outcome. Ann Saudi Med 1994; 14: 483-485.

13. Jaiswani $G$ and Kumar R. Impact of age on outcome of type 1 Tympanoplasty. Otolaryngology online journal. 2014; 4 (4): 129-134.

14. Smyth GDL. Toynbee Memorial Lecture 1992: facts and fantasies in modern otology: the ear doctors dilemma. J Laryngol Otol 1992; 106: 591-596.

15. Sheehy JL and Anderson RG. Myringoplasty: A Review of 472 Cases. Ann Otol Rhinol Laryngol 1980; 89 (4): 331-334.

16. Warrren YA, White $B$ and Charleston SC. "Type1 - tympanoplasty; influ’encing factors" Laryngoscope 1984; 94: 916-919.

17. Joshi RR, Jha AK, Rijal AS, Dhungana A and Shrestha KK. Hearing Evaluation After Myringoplasty At Nepal Medical College and Teaching Hospital. Journal of Nobel Medical College 2013; 2 (3): $36-42$.

18. Gupta N and Mishra RK. Tympanoplasty in children. Indian
Journal of Otolaryngology and Head and Neck Surgey 2002; 54 (4): 271-273.

19. Albera R, Milan F, Riontino E, Giordano L, Gervasio CF, Bussi M, et al. Myringoplasty in children: a comparison with an adult population. Acta Otorhinolaryngol Ital 1998; 18: 295-299.

20. Lancaster JL, Makura ZGG, Porter G and McCormick M. Paediatric tympanoplasty. J Laryngol Otol 1999; 113: 628-632.

21. Bajaj $Y$, Bais AS and Mukherjee B. Tympanoplasty in children - a prospective study. J Laryngol Otol 1998; 112: 1147-1149.

22. Kessler A, Potsic WP and Marsh RR. Type-1 tympanoplasty in children. Arch Otolaryngol Head Neck Surg 1994; 120: 487-490.

23. Puhakka $\mathrm{H}$, Virolainers $\mathrm{E}$ and Rahko $\mathrm{T}$. Long term results of myringoplasty with temporalis fascia. J Laryngol Otol 1979; 93: 1081-1086.

24. Feroze K K, Rejee R E and Sajilal S M. Assessment of factors affecting the outcome of Myringoplasty and type 1 tympanoplasty. International Journal of Biomedical Research 2014; 5(5): 340-343

25. Lee $P$, Kelly $G$ and Mills RP. Myringoplasty: does the size of the perforation matter? Clin Otolaryngol Allied Sci 2002; 27:331-334.

26. Gersdorff M, Garin P, Decat M and Juantegui M. Myringoplasty: Long-Term Results in Adults and Children. Am $\mathrm{J}$ Otol 1995;16(4).532-535

27. Halik JJ and Smyth GD. Long-term results of tympanic membrane repair. Otolaryngol Head Neck Surg 1988; 98:162-169.

28. Nagle S K, Jagade M V, Gandhi S R and Pawar PV. Comparative study of outcome of Type I Tympanoplasty in dry and wet ear. Indian J Otolaryngol Head Neck Surg 2009; 61:138-140.

29. Vijayendra H, Rangam CK and Sangeeta R. Comparative study of Tympanoplasty in wet perforation v/s totally dry perforation in tubotympanic disease. Indian J of Otolaryngol Head Neck Surg 2006;58 (2): 165-167.

30. Zakaria S, Ahmed M, Khabiruddin P, Islam R and Joarder AH. Factors affecting surgical outcome of myringoplasty. Bangladesh Journal of Otorhinolaryngology 2011; 17(2): 82-87.

31. Merchant SN, Rosowski JJ and Mckenna MJ. Tympanoplasty. Op Tech Otolaryngol Head Neck Surg 2003; 14:224-236.

32. Nirwan $S$ and Somashekara KG. A Study of Hearing Improvement after Tympanoplasty by means of Pure Tone Audiometry. Journal of Evidence Based Medicine and Healthcare 2015; 2(2): 113-122.

33. Palva T and Ramsay H. Myringoplasty \& Tympanoplasty result related to training \& experience. Clinical Otolaryngology \& Allied Sciences 1995; 20: 329-335.

34. Sirena E, Carvalho B, Buschle M and Mocellin M. Timanoplastia Myringoplasty Type 1 and in Residency Surgical Results and Audiometric. Int Arch Otorhinolaryngol 2010;14(4):417-421.

35. Doyle PJ, Schleuning AJ and Echevarria J. Tympanoplasty: should grafts be placed medial or lateral to the tympanic membrane. Laryngoscope 1972; 82:1425-1430.

36. Uguz MZ, Onal K, Kazikdas KC and Onal A. The influence of smoking on success of tympanoplasty measured by serum cotinine analysis. Eur Arch Otorhinolaryngol 2008;265(5):513-516. 